\title{
A Questionnaire Survey on Parent's Awareness Regarding Childhood Neurodevelopmental Disorder
}

\author{
Bishnu Prasad Mandal, Yao Yang and Jingyi Fan* \\ Department of Pediatrics, Zhongnan Hospital, Wuhan University, China \\ *Corresponding author: Jingyi Fan, Department of Pediatrics, Zhongnan Hospital of Wuhan University, Wuhan 430072, \\ China
}

\begin{abstract}
Background: Neurodevelopmental disorders (NDDs) are growing worldwide in both developed and developing countries. Parents are primary caregivers to recognize the signs and symptoms of children's behavior or mental -illness. This study is to obtain basic knowledge and awareness about NDDs in children in Nepali community. People in Nepali community have various religions and outdated belief. This study analyzes misconceptions and factors that influence the knowledge regarding NDDs among general populations, which can help to build early recognition and give support towards families with children diagnosed as mental and psychiatric disorders.
\end{abstract}

Methods: This is a descriptive study conducted among parents of children visited in out-patients department in Nirmala Devi hospital. This survey is based on questionnaire interview with parents regarding socio-demographic information and their knowledge and opinion about NDDs. A total of 500 parents were recruited. Data were collected in excel sheet and analyzed by using Statistical Package for Social Sciences (SPSS)

Results: Among our study population, $54.4 \%$ were female and $45.4 \%$ of them were from age 30 to 39 years. The majority of participants $(57.8 \%)$ live in village, $75.6 \%$ were Hinduism and $52.2 \%$ were formal educational status. In general, the participants' knowledge and opinions regarding NDDs were poor. When asked about autism symptoms, $65.4 \%$ of the female respondents were more positive than the male counterparts. When comparison of religion and mental illness are related to God, all religions of respondents were positive. Residency from both city and village agreed that fear of using drugs for treatment of psychiatric disorder resulted from negative media coverage. Highly educated respondents were more likely to consider psychiatric illness as treatable where as formal educated respondent take it the other way.
Conclusion: Public knowledge and awareness regarding NDDs need to improve. Formal educated participants should be the target for mental health education and several misconceptions. Anti-stigma and mental health knowledge programmed should be increased in public and community to improve the quality of life.

\section{Keywords}

Behavioral disorder, Mental illness, General population, Public knowledge

\section{Introduction}

Neurodevelopmental disorders (NDDs) are common and are the fastest growing disabilities of psychiatric condition in early childhood and adolescence [1]. Families and the society may play important role in helping children with behavioral or mental illness and psychiatric disorder. The relationship between family member and developmental disorder children may be the closest [2]. It is important that parents must know the knowledge about childhood neuro-developmental disorder. Proper identification and early diagnosis of childhood neurodevelopmental disorder can do great help to children with this disease. Society leaders and healthcare professionals have urgently need to promote knowledge and awareness of children developmental disabilities. A survey by Ales hemi MA, et al. demonstrated that public knowledge and awareness of autism as a childhood disability need to be improved [3]. Children's developmental disabilities are mostly seen in low and middle income countries [4]. American Psychiatric Association (APA) and Statistical Manual of Mental Disorders fifth edition (DSM-5) firstly describes developmental disabilities as a

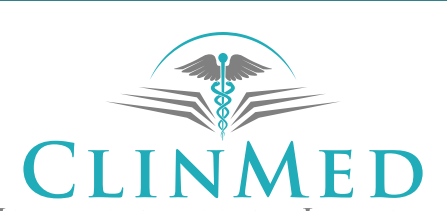

INTERNATIONAL LIBRARY
Citation: Mandal BP, Yang Y, Fan J (2019) A Questionnaire Survey on Parent's Awareness Regarding Childhood Neurodevelopmental Disorder. Int J Pediatr Res 5:052. doi.org/10.23937/2469-5769/1510053 Accepted: April 22, 2019: Published: April 24, 2019

Copyright: (C) 2019 Mandal BP, et al. This is an open-access article distributed under the terms of the Creative Commons Attribution License, which permits unrestricted use, distribution, and reproduction in any medium, provided the original author and source are credited. 
group of disorders that manifest in early developmental period and is characterized by wide range of developmental deficits which include impairments of personal, social and academic or occupational functioning, delays in language skills and poor motor skills [5]. These deficits will persist lifelong with poor health outcome of children and impaired quality of life of their families [6]. Neurodevelopmental disorder is broad terms that include Autism Spectrum Disorder (ASD), Attention Deficit Hyperactivity Disorder (ADHD), Intellectual Disability (ID), Learning disabilities (LD), motor/tic disorders, cerebral palsy, and hearing and vision abnormalities [7]. The estimated prevalence of neurodevelopmental disorder ranges from 5-9\% [8,9]. Among all developmental disabilities, ASD and ADHD are the most common developmental disorders. The current prevalence of ASD is $0.6-3.5 \%$ in United Kingdom (UK), 0.5-2.5\% in United States of America (USA) and that of ADHD is $0.5-2.2 \%$ in UK, 2.0-16.1\% in USA [10]. Developmental disabilities are likely to caused by complex genetic and biological or environmental risk factors [11]. The early recognition and intervention of developmental disorder in children help with treatment and improvement of good health for children [12].

Nepal is a small landlocked country with extraordinary geographical variation situated in South Asia. Mental health in Nepal is one of the least prioritized areas of the health sector; the majority of people think that the person suffering from mental health illness is mad and unfit to live in the society. In Nepalese community, mental health problems are highly stigmatized [13], and people hesitate about consulting mental health professionals and getting appropriate treatment. In Nepal, there are no specific psychiatric centers for children either. The diagnosis and treatment of developmental disorders are provided by pediatricians, physicians, psychologists and neurologists. Due to this situation, most children with neurodevelopmental disorder are not diagnosed properly thus they escape from proper treatment. To date, there is no large scale survey about NDD carried out in Nepal, even though the public generally perceive mental or psychiatric illness are social and economical burden for children and families. Epidemiological studies on developmental disorder are lacking in Nepal; the exact prevalence is still unknown [14]. One of the earliest descriptive studies indicated that the prevalence of children with development and behavioral problem is about $8.5 \%$ [15]. There are still no studies carried out on these issues in our region. These types of studies can spread information and awareness to people with children diagnosed with developmental disorder. The aim of this study is to know the knowledge and opinion of parents of children suffering from neurodevelopmental disorder in our community.

\section{Methods}

This is a descriptive cross-section survey based on questionnaire interview. A total of 40 -items questionnaire was designed for this survey. The survey questionnaire was divided into two sections. The first section included participant's demographic information such as age, gender, religion, education status and residency. The second section included participant's knowledge, opinion about behavioral or mental illness and psychiatric disorder according to DSM-5 diagnostic criteria. Each item in the second section was responded to on Likert-response scales anchored from 1 (strongly disagree), 2 (basically disagree), 3 (neutral), 4 (basically agree) and 5 (strongly agree). The research was conducted in Nirmala Devi Memorial Hospital and Technical College Janakpurdham Nepal. A total of 500 participants were included in this study by using questionnaire interview either face-to-face or self completed by participants, at 15-20 minutes duration. The questionnaire was explained to the participants before the interview. After all data were collected, we coded "strongly disagree" and "basically disagree" as "disagree", basically agree" and "strongly agree" as agree" for subsequent statistical analysis. Data were collected in excel sheets and analyzed by using Statistical Package for Social Sciences (SPSS).

\section{Results}

A total of 500 participants were included in this study. Two questionnaires were incomplete and then excluded from data. Demographic information of participant is summarized in Table 1 . The age distribution of all participants was different. The majority of the respondents were between 30 and 39 -years-old $(45.4 \%$, $\mathrm{n}=500)$, and most of them were women $(54.4 \%, \mathrm{n}=$ 500). In this study, participants' religious beliefs were

Table 1: Demographic characteristics of participants $(n=500)$.

\begin{tabular}{|c|c|c|c|}
\hline Category & & Frequency & Percent (\%) \\
\hline \multirow[t]{2}{*}{ Gender } & Male & 228 & 45.6 \\
\hline & Female & 272 & 54.4 \\
\hline \multirow[t]{4}{*}{ Age } & 20-29 years & 168 & 33.6 \\
\hline & 30-39 years & 227 & 45.4 \\
\hline & $40-49$ years & 63 & 12.6 \\
\hline & $>50$ years & 42 & 8.4 \\
\hline \multirow[t]{3}{*}{ Religion } & Hindu & 378 & 75.6 \\
\hline & Islam & 89 & 17.8 \\
\hline & Buddhism & 33 & 6.6 \\
\hline \multirow[t]{2}{*}{ Residency } & Village & 289 & 57.8 \\
\hline & City & 211 & 42.2 \\
\hline \multirow{5}{*}{$\begin{array}{l}\text { Academic } \\
\text { qualification }\end{array}$} & Primary school & 83 & 16.6 \\
\hline & Junior school & 178 & 35.6 \\
\hline & Senior school & 103 & 20.6 \\
\hline & College & 98 & 19.6 \\
\hline & $\begin{array}{l}\text { Master degree or } \\
\text { above }\end{array}$ & 38 & 7.6 \\
\hline
\end{tabular}


Table 2: Responses of whole sample regarding explanation of behavioral or mental and psychiatric disorder $(n=500)$.

\begin{tabular}{|c|c|c|c|c|c|c|c|}
\hline & Statements & Res & nses & & & & \\
\hline & & Agre & & Disa & & Neu & \\
\hline & & No. & $\%$ & No. & $\%$ & No. & $\%$ \\
\hline 1 & $\begin{array}{l}\text { Children's behavioral problems are part of the mental and } \\
\text { psychological health problems }\end{array}$ & 169 & 33.8 & 267 & 53.4 & 64 & 12.8 \\
\hline 2 & $\begin{array}{l}\text { Adolescents' behavioral problems are part of the mental and } \\
\text { psychological health problems }\end{array}$ & 255 & 51 & 175 & 35 & 88 & 17.6 \\
\hline 3 & ADHD is a kind of mental or psychiatric illness & 154 & 30.8 & 186 & 37.2 & 160 & 32 \\
\hline 4 & ASD is a neurodevelopmental disorder & 135 & 27 & 202 & 40.4 & 160 & 32 \\
\hline 5 & $\begin{array}{l}\text { Depression symptoms in children and adolescents are similar to that } \\
\text { in adults }\end{array}$ & 144 & 28.8 & 287 & 57.4 & 69 & 13.8 \\
\hline 6 & $\begin{array}{l}\text { The symptoms of anxiety in children and adolescents are similar to } \\
\text { that in adults }\end{array}$ & 140 & 28 & 290 & 58 & 70 & 14 \\
\hline 7 & Drugs can change the chemical substances of the brain & 416 & 83.2 & 17 & 3.4 & 67 & 13.4 \\
\hline 8 & Psychotherapy can change the chemical substances of the brain & 59 & 11.8 & 374 & 74.8 & 67 & 13.4 \\
\hline
\end{tabular}

also taken into account and it was found that the majority of participants were Hindu $(75.6 \%, n=500)$ and more participants lived in villages $(57.8 \%, \mathrm{n}=500)$. In aspect of educational status, $35.6 \%$ had received formal education, and $7.6 \%$ had a master's degree or above.

\section{Respondents' explanation of behavioral or mental and psychiatric disorder}

Table 2 shows that $33.8 \%(n=500)$ of the respondents agreed the statement that children's behavioral problems were part of their mental and psychological health problems. In aspect of adolescents, 51\% ( $n=500)$ agreed as a behavioral problems are a part of mental and psychological health problems. The respondents had almost the same attitude towards ADHD (37.2\% disagree and $30.8 \%$ agree) and ASD (40.4\% disagree and $27 \%$ agree) as a mental neurodevelopmental disorder. Thirty two percents $n=500$ of respondents were neutral as concerning the both statements. On the other hand, over half of our respondents said that the symptoms of depression and anxiety in children and adolescents were similar to that in adults. The majority $(83.2 \%, n=500)$ of respondents agreed with the statement that drugs can change the chemical substances of the brain, while a minority disagreed $(3.4 \%, \mathrm{n}=500)$, but the majority disagreed with the statement that psychotherapy can change the chemical substances of the brain $(74.8 \%, \mathrm{n}$ $=500)$.

As is shown in Figure 1, in respect of respondents' personal opinion, the majority of respondents agreed that depression $(77.2 \%, n=500)$ and anxiety $(75.4 \%, n$ $=500$ ) are a mental and psychiatric disorder and a few respondents disagreed with depression $(9 \%, n=500)$ and anxiety $(8.6 \%, n=500)$ are mental or psychiatric illness. Over $60.4 \%(n=500)$ of respondents disagreed and $24 \%$ ( $n=500$ ) agreed with the statement that children can suffer from depression, where as $15.6 \%$ ( $n=500$ ) were neutral. There were $32.8 \%(n=500)$ of respondents agreed regarding the statement that adolescents can suffer from depression and adolescents can suffer from anxiety $35.6 \%(n=500)$. However, $74 \%$ of respondents were disagreed with the statement that children can suffer from anxiety. There were $63.8 \%$ (n $=500$ ) of respondents agreed regarding with mental retardation is a kind of mental and psychiatric illness.

\section{Comparison of respondents' gender (father and mother) and knowledge of autism symptoms}

Generally, both the father and mother agreed that their knowledge about symptoms of behavioral or mental and psychiatric disorder was sufficient. When asked about the difficulties autism children have in playing with other children, female respondents (65.4\%, $\mathrm{n}=272$ ) were slightly higher than male respondents $(50.0 \%, n=228)$ as shown in Figure 2.

\section{Comparison of religions and the statement that behavioral or mental illnesses someone suffers in family are related to God}

In total obtained data, most people in all religions, including Hinduism $(77.2 \%, \mathrm{n}=378)$, Islam $(86.5 \%$, $\mathrm{n}=89)$ and Buddhism (72.7\%, $\mathrm{n}=33$ ) believed that the behavioral or mental illness of adults, children or adolescents was related to god in the family; whereas a small amount of respondents didn't agree with this statements. This is shown in Figure 3.

\section{Comparison of respondent's residency and fear of using drugs to treat children's and adolescents behavior or mental and psychiatric illness due to negative media coverage}

Among most residents from both city and village, respondents' fear of using drugs to treat behavioral and mental disorder in children and adolescents is due to negative media coverage. The degree of agreement in village residents is relatively higher than that in city residents, as shown in Figure 4. 


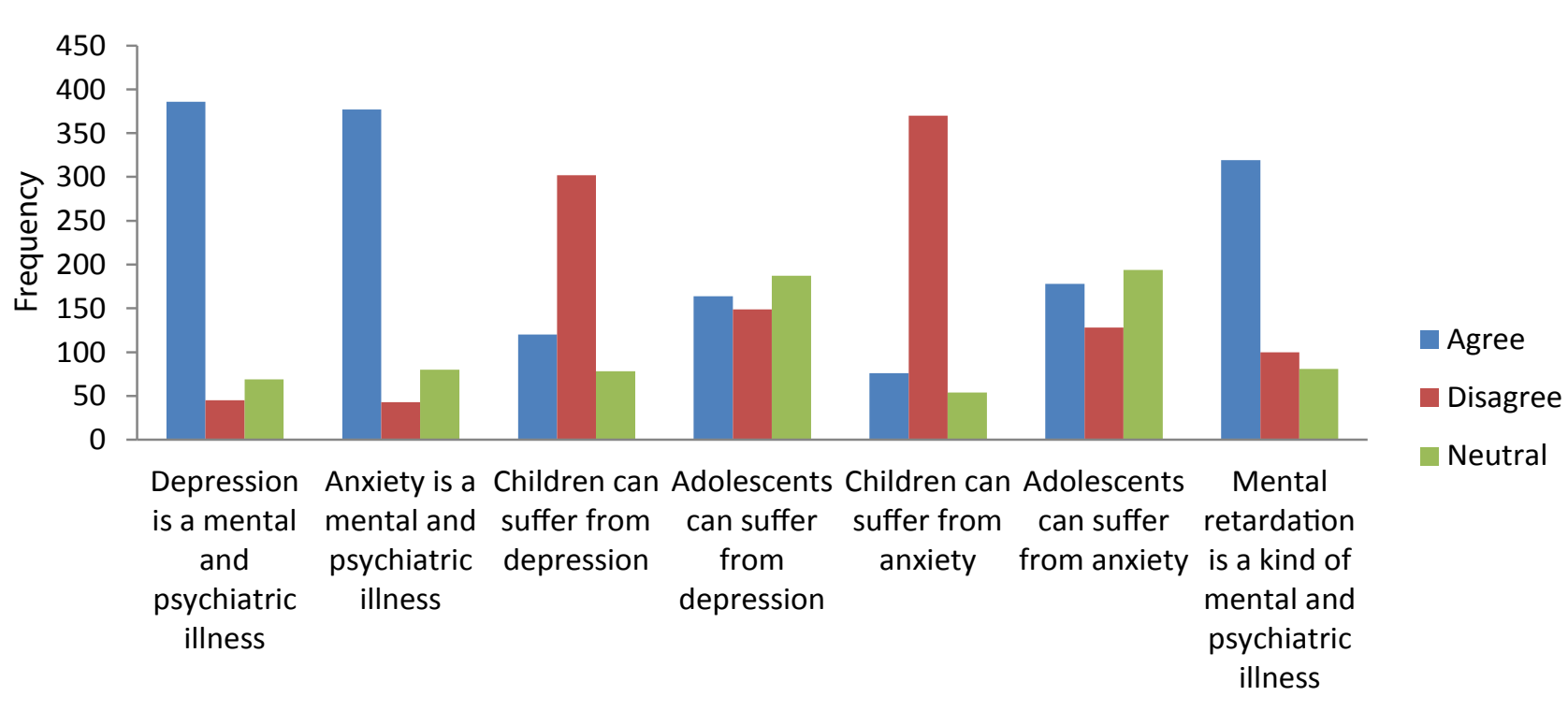

Statements

Figure 1: Opinion of respondents about behavior or mental and psychiatric disorder $(n=500)$.

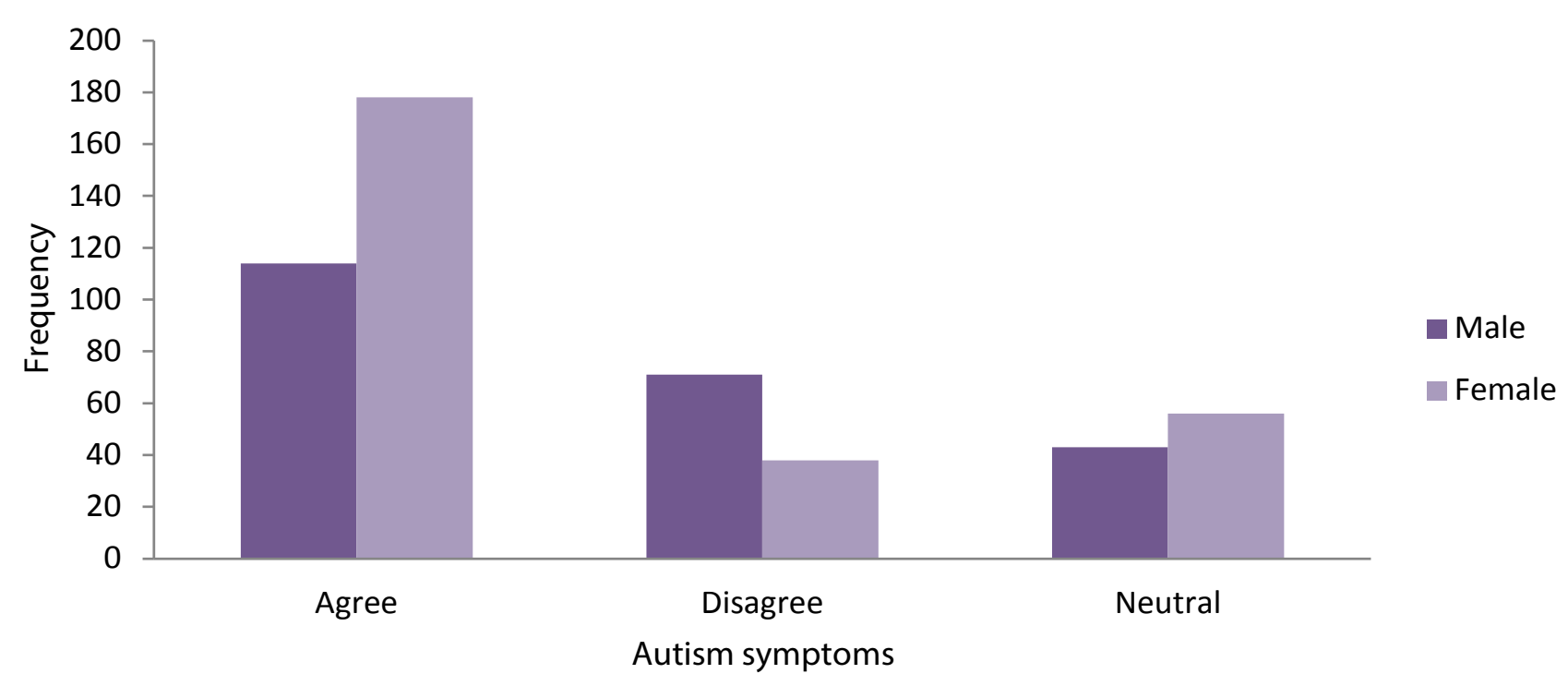

Figure 2: Comparison of gender with knowledge of autism symptom $(n=500)$.

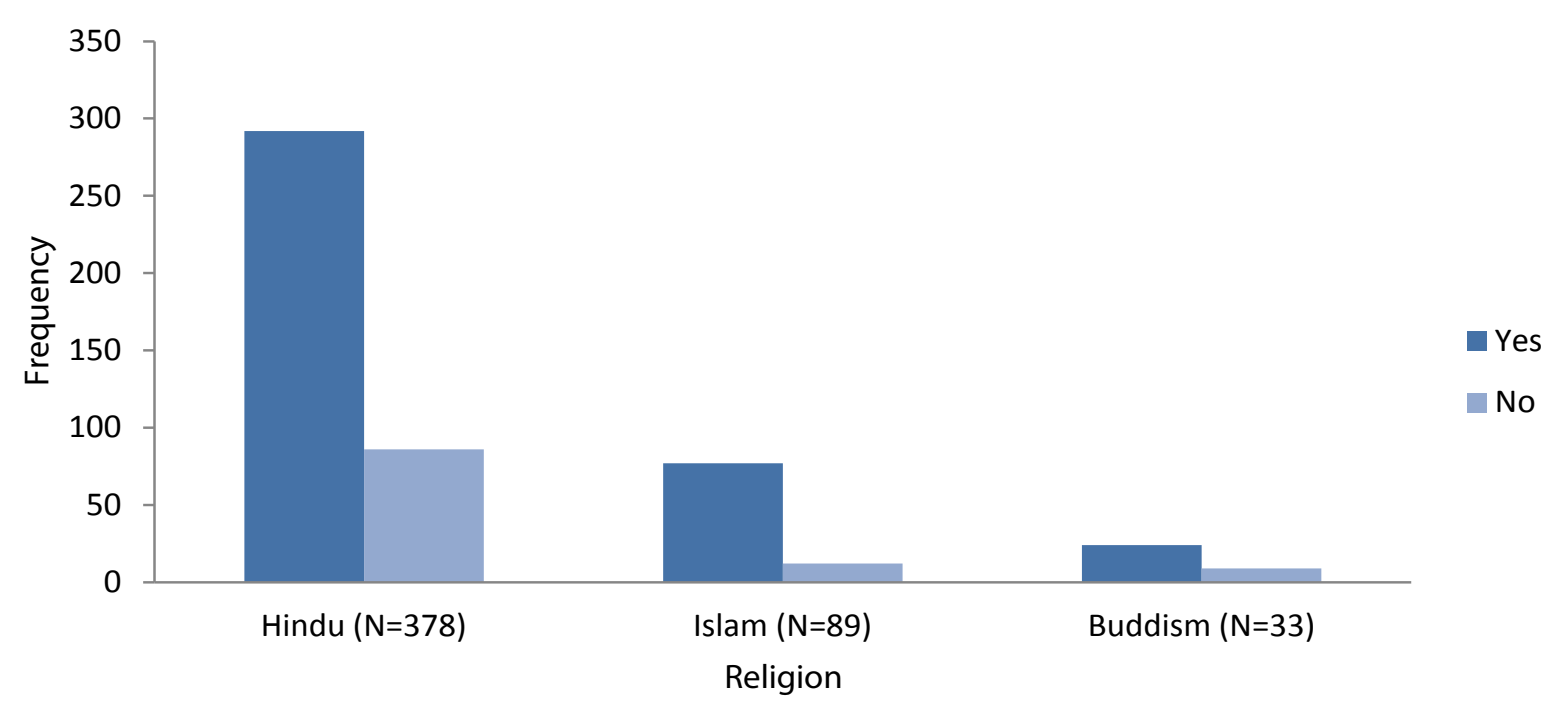

Figure 3: Comparison of religion with behavioral or mental illness is related to god in family $(n=500)$. 


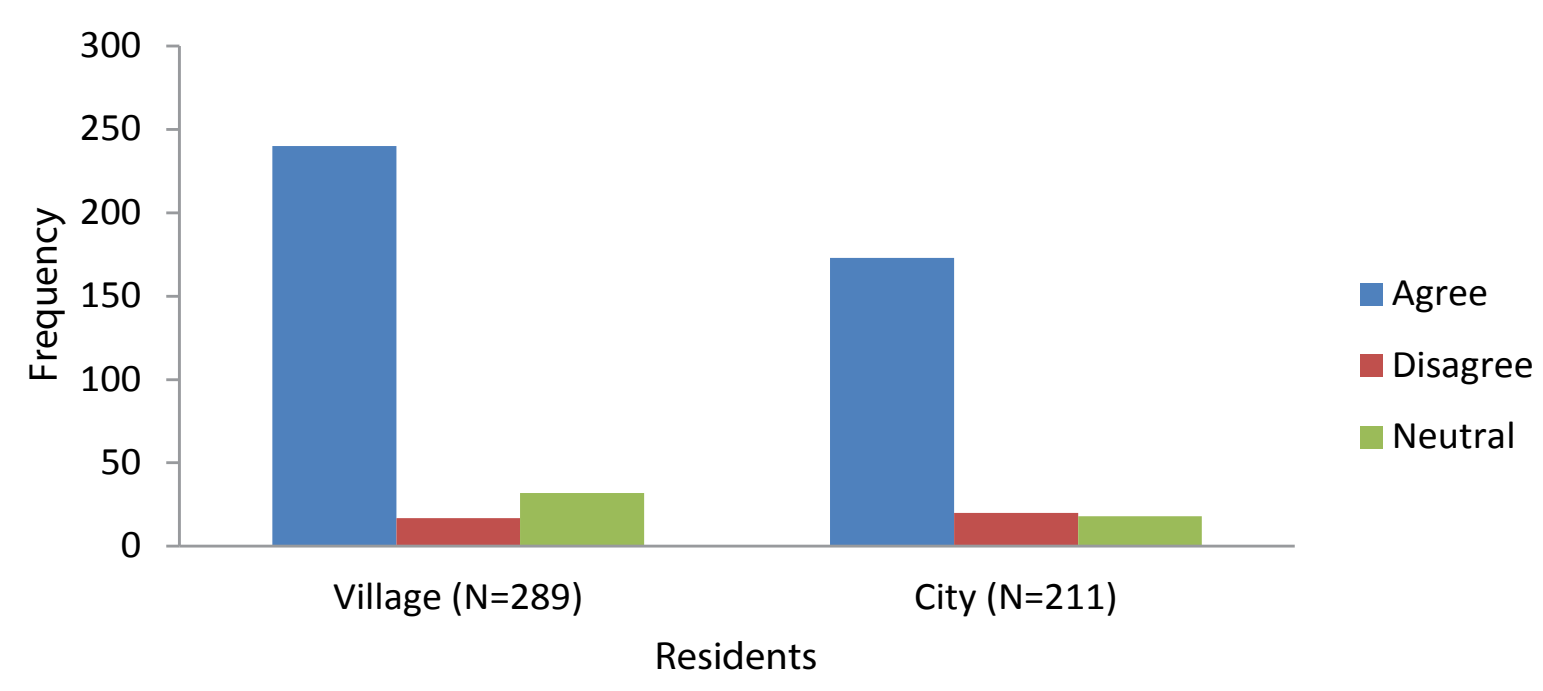

Figure 4: Comparison of residents with fear to use of drugs $(n=500)$.

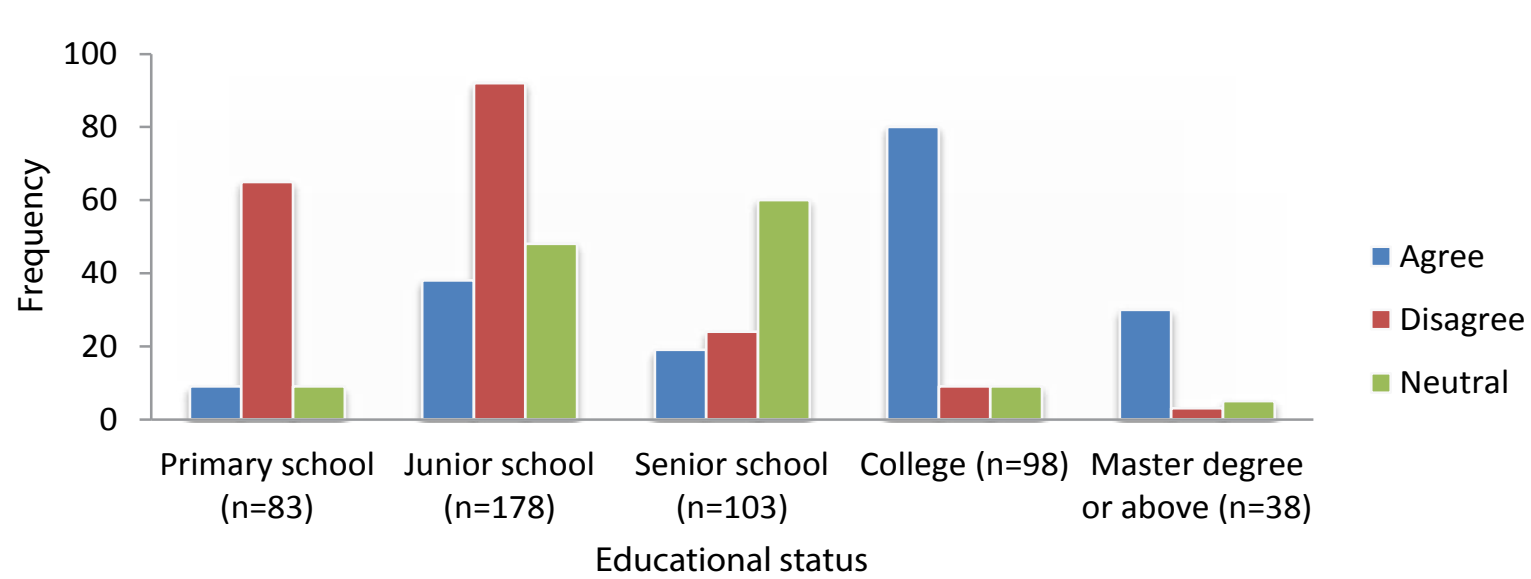

Figure 5: Comparison of education with psychiatric disorder is treatable $(n=500)$.

\section{Comparisons of respondents' educational status with the statement that mental or behavioral and psychiatric illnesses are curable}

As can be seen from Figure 5, compared with primary school $(78.3 \%, \mathrm{n}=83)$ and junior high school $(51.7 \%$, $\mathrm{n}=178)$, college students receiving higher education $(81.6 \%, n=98)$ and master's $(78.9 \%, n=38)$ agree that behavioral or mental diseases are treatable.

\section{Discussion}

Mental health is a fundamental field in many countries and a largely rejected field in many poor countries. Nepal is a small country; only a few hospitals have inpatient facilities for children with mental illness, and most hospitals use outpatient services. This is a questionnaire based survey to find out parents' knowledge and opinion on behavioral or mental and psychiatric disorder. The majority of the respondents were between 30 and 39-years-old, and most of them were female. Hinduisms was the main religion of the participants, and most respondents of various educational levels obtained in this study lived in villages.

\section{Knowledge of behavioral or mental and psychiatric disorder}

In this study, parent's knowledge about children and adolescents' behavior problem were different (Table 2). It was very difficult to identify children's signs and symptoms of mental illness and to distinguish between normal and abnormal childhood behavior. The adolescents signs and symptoms of mental disorder are much more overlap even though adolescents have sufficient vocabulary to explain their problems to the parents [16]. The study also found that parents didn't agreed that ADHD and ASD were neurodevelopmental disorder. These findings are similar with a study of autism knowledge among the health care in Lahore, Pakistan [17]. This study also found that the majority of respondents disagreed that depression and anxiety symptoms in children and adolescents were similar to adults. During childhood parents can't recognize the sign and symptoms of mental illness $[18,19]$. The majority of respondents agreed that drugs can change the chemical substance of the brain but there are many risk factors; however, most respondents disagreed with psychotherapy $[20,21]$. We should pay great attention to 
the impact of chronic public stigmatization and improve the level of education by popularizing the knowledge of mental and psychiatric disorder in community.

\section{Opinion towards mental and psychiatric disorder}

In our questionnaire respondents' opinions are highly variable according to different statements. The majority of respondents agreed that depression and anxiety is a mental and psychiatric illness, where-as they disagreed that children can suffer from depression and anxiety. When asked about adolescents' depression and anxiety, most of the respondents were neutral. Children and adolescents are less able to express their thoughts to others, which may be the reason why the participants misinterpreted the symptoms. Another reason may be the lack of mental health literacy and impact of stigma in society. In our opinion, people need to aware of the importance of mental health and reduce stigma [3]. Individuals with mental illness lack of various skills and have behavioral and emotional problem, so the majority of respondents agreed the statements that mental retardation is a kind of mental and psychiatric illness [22]. This finding is correlated with a study conducted in Karachi, Pakistan to investigate the knowledge and awareness among parents, the study also found insufficient knowledge and awareness about mental disorder [23]. This study also identified that a slightly greater number of female respondents know about autism symptom in comparison to male. Mothers haves better knowledge regarding autism as indicated in studies conducted in Australia [24].

Nepal is a Hinduism country even though; citizens of other religions also exist. From the ancient times, mental illnesses are highly stigmatized in our country. In our community, mental illness is more related to god rather than a medical problem. People have misunderstandings about black magic. All culture in our country discriminates against mental health. Individuals in families with mental illness tend to have less support [25]. There are many religious activities such as praying to god and engaging in religious rituals, which produce positive results and are the primary ways to deal with mental health illnesses [26]. All religions prohibit behaviors and lifestyles that affect our health, such as eating, smoking and drug use. Most people in our country think of religious activities as medication. It can help to reduce tension, stress, improve self knowledge and reduce fear. People have belief in spirituality and they think that spiritual direction is the special relationship between God and human beings, which promotes personal growth, meaning of life and improves psychological health [27]. In this study, Muslim religions also think that mental illnesses are related to God. They believe that all events in life are influenced by God such as virtuous and pious [28].

Negative image of social media had an impact on both village and city residents obtained in our studies. The media created mental health stigma and discrimination, thus it influenced people's knowledge and attitudes towards mental health. The media emphasized that individuals with mental health problem are fear ostracized and ridiculed. The media created discrimination towards people seeking help for mental illness [29]. The relationship between media and community makes it seems that individuals with mental illness are prone to violence and unpredictable attack. These facts are involved in survey of general population and mental health [30]. A study suggested that social media depraved mental health in younger generation, as in several aspects including loneliness and suicidal thoughts [31]. The negative media influence is the basic cause of the medications used to treat mental illness.

Our study also compared the respondents' education level with what they think about the treatment of psychiatric disorder. The highly educated respondents suggested that mental and behavioral disorder was treatable. The educated person may think mental health services improve health of who suffer from mental and psychiatric illness. Maybe educated individuals don't believe in stigma and misconceptions. They don't concentrate on fear and help to improve mental health system [32]. Formal educated respondents in this study think mental disorder is not treatable. Due to lack of enough education and experiences of medical camps the reason may be that they do not know about mental treatment. A study conducted in college students found that they improve help seeking towards mental illness in general education [33].

\section{Conclusion}

Public knowledge and awareness regarding NDDs need to be improved. Formal educated participants should be the target for improve mental health education, stigma and discriminations. Anti-stigma and mental health knowledge programmed should be increased in public and community to improve the quality of life.

\section{Acknowledgement}

We would like to thank Professor Dr. Jing Yi Fan for providing questionnaire to conduct the study.

\section{Conflict of Interest}

The author declares that there has no conflict of interest concerning this article.

\section{References}

1. Gregory M (2012) Centers for disease control and prevention. Prevalence of autism spectrum disorders autism and developmental disabilities monitoring network. Austral J Appl Sci MMWR 61: 174-193.

2. Ritzema AM, Lach LM, Nicholas D, Sladeczek IE (2018) A model of well-being for children with neurodevelopmental disorders: Parental perceptions of functioning, services, and support. Child Care Health Dev 44: 240-248. 
3. Alsehemi MA, Abousaadah MM, Sairafi RA, Jan MM (2017) Public awareness of autism spectrum disorder. Neurosciences (Riyadh) 22: 213-215.

4. Suresh Kumar Rathi, Marj R Francis (2012) Neurodevelopmental disorders among Indian children: Needs attention. Electronic Physician 4: 1-7.

5. Abubakar A, Ssewanyana D, Newton CR (2016) A systematic review of research on autism spectrum disorders in sub-saharan Africa. Behav Neurol.

6. Ashley C Woodman, Helena P Mawdsley, Penny Hauser Cram (2015) Parenting stress and child behavior problems within families of children with developmental disabilities. Res Dev Disabil 36C: 264-276.

7. Khoury Brigitte, Cary Kogan, Sariah Daouk (2017) International classification of diseases 11th edition (ICD11). Springer International Publishing 112: 1-6.

8. Lamsal Ramesh, Daniel J Dutton, Jennifer D Zwicker (2018) Using the ages and stages questionnaire in the general population as a measure for identifying children not at risk of a neurodevelopmental disorder. BMC Pediatr 18: 122.

9. Arim RG, Anton R Miller, Anne Guèvremont, Lucyna M Lach, Jamie C Brehaut, et al. (2017) Children with neurodevelopmental disorders and disabilities: A population-based study of healthcare service utilization using administrative data. Dev Med Child Neurol 59: 12841290.

10. Megan Cleaton Mary Ann, Amanda Kirby (2018) Why do we find it so hard to calculate the burden of neurodevelopmental disorders. J Child Dev Disord 04: 10.

11. Felice Alessia De, Laura Ricceri, Aldina Venerosi, Flavia Chiarotti, Gemma Calamandrei (2015) Multifactorial origin of neurodevelopmental disorders: Approaches to understanding complex etiologies. Toxics 3: 89-129.

12. Cioni Giovanni, Emanuela Inguaggiato, Giuseppina Sgandurra (2016) Early intervention in neurodevelopmental disorders: Underlying neural mechanisms. Dev Med Child Neurol 58: 61-66.

13. Mukolo Abraham, Craig Anne Heflinger, Kenneth A Wallston (2010) The stigma of childhood mental disorders: A conceptual framework. J Am Acad Child Adolesc Psychiatry 49: 92-198.

14. Hossain Mohammad Didar, Helal Uddin Ahmed, M M Jalal Uddin, Waziul Alam Chowdhury, Mohd S lqbal, et al. (2017) Autism spectrum disorders (ASD) in South Asia: A systematic review. BMC Psychiatry 17: 281.

15. Rimal Hem Sagar, Archana Pokharel, Vijay Saha, Arun Giri, Basudha Ghimire, et al. (2014) Burden of developmental and behavioral problems among children - a descriptive hospital based study. Journal of Nobel Medical College 53: 45-49.

16. Lawrence David, Sarah Johnson, Jennifer Hafekost, Katrina Boterhoven de Haan, Michael Sawyer, et al. (2015) The mental health of children and adolescents child and adolescents. Report on the second Australian child and adolescent survey of mental health and wellbeing Department of Health, Canberra.

17. Imran Nazish, Mansoor R Chaudry, Muhammad W Azeem, Muhammad R Bhatti, Zaidan I Choudhary, et al. (2011) A survey of autism knowledge and attitudes among the healthcare professionals in Lahore, Pakistan. BMC Pediatr 11: 107.

18. Merikangas Kathleen Ries, Erin F Nakamura, Ronald C
Kessler (2009) Epidemiology of mental disorders in children and adolescents. Dialogues Clin Neurosci 11: 7-20.

19. Seyyed Salman Alavi, Masoud Ferdosi, Hamed Alaghemandan, Fereshte Jannatifard, Mehdi Eslami, et al. (2012) Behavioral addiction versus substance addiction: Correspondence of psychiatric and psychological views. Int J Prev Med 4: 290-294.

20. Bohman Hannes, Ulf Jonsson, Aivar Päären, Anne Liis Von Knorring, Gunilla Olsson, et al. (2010) Long-term follow-up of adolescent depression. A population-based study. Ups J Med Sci 115: 21-29.

21. Sheth Hitesh C (2009) Mind, brain and psychotherapy. Indian J Psychol Med 31: 11-15.

22. Suzanne Steffenburg, Christopher Gillberg, Ulf Steffenburg (1996) Psychiatric disorders in children and adolescents with mental retardation and active epilepsy. Arch Neurol 53: $904-912$.

23. Anwar Muhammad Salar, Mahnoor Tahir, Khushboo Nusrat, Muhammad R Khan (2018) Knowledge, awareness, and perceptions regarding autism among parents in Karachi, Pakistan. Cureus 10: e3299.

24. Allen, Terence V Bowles, Linda Weber (2014) Stress associated with parenting a child with autism spectrum disorder. Autism Insights 1: 11094.

25. Kapungwe A, S Cooper, J Mwanza, L Mwape, A Sikwese, et al. (2010) Mental illness-stigma and discrimination in Zambia. Afr J Psychiatry (Johannesbg) 13: 192-203.

26. Michelle J Pearce, Deborah Medoff, Ryan E Lawrence, Lisa Dixon (2016) Religious coping among adults caring for family members with serious mental illness. Community Ment Health J 52: 194-202.

27. Mohr Sylvia (2011) Integration of spirituality and religion in the care of patients with severe mental disorders. Religions 2: 549-565.

28. Okasha Ahmed, Tarek Okasha (2012) Religion, spirituality and the concept of mental illness. Actas Esp Psiquiatr 40: 73-79.

29. Stuart H (2006) Media portrayal of mental illness and its treatments: What effect does it have on people with mental illness? CNS Drugs 20: 99-106.

30. Pirkis Jane, Catherine Francis (2012) Mental illness in the news and the information media a critical review. Commonwealth of Australia 978-1-74241-755-4.

31. Berryman Chloe, Christopher J Ferguson, Charles Negy (2018) Social media use and mental health among young adults. Psychiatr Q 89: 307-314.

32. Dixon LB, Holoshitz Y, Nossel I (2016) Treatment engagement of individuals experiencing mental illness: Review and update. World Psychiatry 15: 13-20.

33. Turetsky Kate M, Catherine A Sanderson (2018) Comparing educational interventions: Correcting misperceived norms improves college students' mental health attitudes. Journal of Applied Social Psychology 48: 46-55. 